\title{
Magnesium-containing mixed coatings on zirconia for dental implants: mechanical characterization and in vitro behavior
}

C) The Author(s) 2015

Reprints and permissions: sagepub.co.uk/journalsPermissions.nav DOI: $10.1177 / 0885328215572428$ jba.sagepub.com

@SAGE

\author{
Karoline Pardun', Laura Treccani', Eike Volkmann', \\ Philipp Streckbein ${ }^{2}$, Christian Heiss ${ }^{3,4}$, Juergen W Gerlach ${ }^{5}$, \\ Stephan MaendI ${ }^{5}$ and Kurosch Rezwan'
}

\begin{abstract}
An important challenge in the field of dental and orthopedic implantology is the preparation of implant coatings with bioactive functions that feature a high mechanical stability and at the same time mimic structural and compositional properties of native bone for a better bone ingrowth. This study investigates the influence of magnesium addition to zirconia-calcium phosphate coatings. The mixed coatings were prepared with varying additions of either magnesium oxide or magnesium fluoride to yttria-stabilized zirconia and hydroxyapatite. The coatings were deposited on zirconia discs and screw implants by wet powder spraying. Microstructure studies confirm a porous coating with similar roughness and firm adhesion not hampered by the coating composition. The coating morphology, mechanical flexural strength and calcium dissolution showed a magnesium content-dependent effect. Moreover, the in vitro results obtained with human osteoblasts reveal an improved biological performance caused by the presence of $\mathrm{Mg}^{2+}$ ions. The magnesiumcontaining coatings exhibited better cell proliferation and differentiation in comparison to pure zirconia-calcium phosphate coatings. In conclusion, these results demonstrate that magnesium addition increases the bioactivity potential of zirconia-calcium phosphate coatings and is thus a highly suitable candidate for bone implant coatings.
\end{abstract}

\section{Keywords}

Zirconia, calcium phosphate, magnesium, bioactivity, implant coating

\section{Introduction}

In the dental and orthopedic field, metal implants such as titanium and its alloys have been extensively studied and established as metallic biomaterials. More specifically, these materials are widely used especially for load-bearing applications due to their superior mechanical properties and good biocompatibility. On the other hand, metallic materials may corrode when implanted and cause toxic reactions in the biological environment. ${ }^{1-3}$ Therefore, ceramics like zirconia (TZ) received increased attention as dental and orthopedic materials because of their excellent corrosion resistance, good biocompatibility, favorable mechanical properties as well as satisfying esthetic requirements. ${ }^{4,5}$ However, for load-bearing applications not only enhanced mechanical properties are of concern. Despite major progress in implant technology, both metallic and ceramic implants fail due to insufficient integration. Weak bone ingrowth caused by formation of fibrous tissue or infections can entail patient discomfort and the unstable implant may need to be surgically removed. Thus, the success of implant materials largely depends on the formation of a mechanically

\footnotetext{
'University of Bremen, Advanced Ceramics, Germany

${ }^{2}$ University Hospital, Justus-Liebig-University Giessen, Department of Cranio-Maxillo-Facial Surgery, Germany

${ }^{3}$ University Hospital of Giessen-Marburg, Department of Trauma Surgery, Germany

${ }^{4}$ Laboratory of Experimental Surgery, Germany

${ }^{5}$ Leibniz Institute of Surface Modification, Germany

Corresponding author:

Laura Treccani, University of Bremen, Am Biologischen Garten 2, 28359

Bremen, Germany.

Email: treccani@uni-bremen.de
} 
stable and strong interface between material and bone tissue. ${ }^{6-9}$

In order to improve the implant-tissue integration, considerable efforts have been devoted to modify the surface characteristics of biomaterials. Among various attempts, calcium phosphate $(\mathrm{CP})$ coatings have been proposed to promote direct attachment to bone tissue. Hydroxyapatite (HA) and tricalcium phosphates (TCP) are promising synthetic materials, that received particular attention due to their bioactivity, positive effect on cell attachment, proliferation and differentiation and thus initiation of bone formation. ${ }^{10-12}$ Although the excellent biological performance is well documented in literature, insufficient mechanical properties and weak bonding strength to the substrate affect its application. ${ }^{13-16}$ To overcome these limitations of pure CP coatings, studies have been carried out with TZ-reinforced HA coatings on titanium to combine good mechanical properties with bioactivity. ${ }^{17,18}$ Our previous study demonstrated improved coating stability and adhesion strength by incorporation of $\mathrm{TZ}$ into $\mathrm{CP}$ due to the formation of a chemical bond at the interface during sintering when applied on $\mathrm{TZ}$ substrates and the prevention of mismatch. ${ }^{19}$

The physico-chemical properties of coatings can be further improved by the addition of bioactive ions naturally present in bone. Hard tissue in human bodies contains a variety of elements such as magnesium $\left(\mathrm{Mg}^{2+}\right)$, potassium $\left(\mathrm{K}^{+}\right)$, fluorine $\left(\mathrm{F}^{-}\right)$, sodium $\left(\mathrm{Na}^{+}\right)$and strontium $\left(\mathrm{Sr}^{2+}\right)$, which likely play important biological roles. ${ }^{20,21}$ Among these elements, magnesium, one of the most important bivalent ions associated with bone tissue, attracted much attention in recent years. Enamel, dentin and bone contain $0.44 \mathrm{wt} \%, 1.23 \mathrm{wt} \%$ and $0.72 \mathrm{wt} \%$ of $\mathrm{Mg}^{2+}$, respectively. ${ }^{22}$ It has been reported that $\mathrm{Mg}^{2+}$ is strongly associated with the mineralization process, in particular during the early stage of osteogenesis and thus affects mechanical properties of bone. Moreover, $\mathrm{Mg}^{2+}$ is essential for cellular and enzymatic reactions, and improves cell behavior in terms of adhesion, proliferation and metabolic activity. $\mathrm{Mg}^{2+}$ is one of the main substitutes for calcium in biological apatites and based on its biological relevance. Many researchers have demonstrated the improvement of bioactivity and stimulatory effects on growth of new bone tissue. ${ }^{23-27}$ Therefore, it is reasonable to believe that $\mathrm{Mg}^{2+}$ incorporation into coatings is likely to improve cell behavior due to a composition close to bone. Thus, it is of crucial importance to investigate the effect of $\mathrm{Mg}^{2+}$ on regulation of dissolution, mechanical strength and osteoblast response.

The aim of our study is to understand the effect of $\mathrm{Mg}$-incorporation in mixed coatings consisting of $\mathrm{TZ}$ and $\mathrm{CP}$ on $\mathrm{TZ}$ substrates prepared by wet powder spraying (WPS). Phase composition and surface morphology of the coatings are evaluated by X-ray diffraction (XRD) and scanning electron microscopy (SEM), respectively. Mechanical strength of the coated samples and adhesion strength test of the coatings are performed, as well as in vitro dissolution behavior and bioactivity in simulated body fluid (SBF). To investigate the cytocompatibility of the coatings, human osteoblasts (HOB) are cultured on the specimen surfaces and proliferation, differentiation and spreading of the cells are studied.

\section{Materials and methods}

All chemicals were purchased from Sigma-Aldrich (Munich, Germany) unless otherwise stated.

\section{Coating preparation on zirconia substrates and coating process}

The preparation of substrates, suspensions and the coating process were carried out in our previous work. ${ }^{19}$ Briefly, the suspensions were prepared by mixing HA (particle size: $151 \mathrm{~nm}$ ), TZ-3YS-E powder (TZ, particle size: $360 \mathrm{~nm}$, Tosoh, Tokyo, Japan) and different amounts of either magnesium oxide $(\mathrm{MgO})$ or magnesium fluoride $\left(\mathrm{MgF}_{2}\right)$ in double-deionized water. Polyacrylic acid was added at a ratio of $12 \mathrm{mg} / \mathrm{g}$ ceramic powder (Syntran ${ }^{\circledR}$ 8220, Interpolymer $\mathrm{GmbH}$, Hassloch, Germany) and the $\mathrm{pH}$ was adjusted to 10 with ammonium hydroxide solution $\left(25 \% \mathrm{NH}_{3}\right.$ basis $)$. The suspensions were homogenized by ultrasonication (Sonifier 450, Branson, Dietzenbach, Germany) for 10 min. For comparison purposes a mixed suspension of $\mathrm{HA}$ and $\mathrm{TZ}$ without magnesium addition was used as reference. The coating compositions are shown in Table 1.

Table I. Coating composition of the mixed coatings in wt\% with magnesium addition.

\begin{tabular}{lllll}
\hline Sample & TZ & $\mathrm{HA}$ & $\mathrm{MgO}$ & $\mathrm{MgF}_{2}$ \\
\hline TZCP & 66 & 34 & - & - \\
TZCPMOI & 66 & 34 & $\mathrm{I}$ & - \\
TZCPMOI.6 & 66 & 34 & $\mathrm{I} .6$ & - \\
TZCPMO2.5 & 66 & 34 & 2.5 & - \\
TZCPMO5 & 66 & 34 & 5 & - \\
TZCPMFI & 66 & 34 & - & 1 \\
TZCPMFI.6 & 66 & 34 & - & 1.6 \\
TZCPMF2.5 & 66 & 34 & - & 2.5 \\
TZCPMF5 & 66 & 34 & - & 5 \\
\hline
\end{tabular}

$\mathrm{HA}$ : hydroxyapatite; $\mathrm{MgO}$ : magnesium oxide; $\mathrm{MgF}_{2}$ : magnesium fluoride; TZCP: zirconia-calcium phosphate. 
Zirconia discs $($ diameter $=15 \mathrm{~mm}$, thickness $=1.7 \mathrm{~mm})$ were fabricated using commercially available $\mathrm{TZ}$ powder (TZ-3YSB-E, Tosoh, Tokyo, Japan) by uniaxially pressing at $38 \mathrm{MPa}$. The zirconia discs were isostatically densified at 1200 bar for $5 \mathrm{~min}$ and subsequently pre-sintered at $1100^{\circ} \mathrm{C}$ for $2 \mathrm{~h}$ in air. Zirconia screws (diameter $=4.5 \mathrm{~mm}$, length $=17 \mathrm{~mm}$ ) were obtained via injection molding from a zirconia feed stock (INMAFEED K1012, INMATEC Technologies GmbH, Rheinbach, Germany) and pre-sintered at $950^{\circ} \mathrm{C}$ for $2 \mathrm{~h}$ in air (Fraunhofer IFAM, Bremen, Germany).

The mixed coatings were deposited by wet powder spraying (WPS) using a double-action airbrush spray gun (BD 183-K, Artistic Life, Boenen, Germany) with an airbrush nozzle of $0.8 \mathrm{~mm}$ in diameter. Coating depositions were performed with a working distance of $200 \mathrm{~mm}$, an air pressure of 2 bar and a relative humidity of $\sim 60 \%$. The coated samples were dried for $24 \mathrm{~h}$ at room temperature and then sintered at $1500^{\circ} \mathrm{C}$ for $2 \mathrm{~h}$ in air.

\section{Coating characterization and mechanical investigation}

All characterization was performed on sintered samples. Surface composition of different coatings was determined by grazing incidence X-ray diffraction (GIXRD) using an Ultima IV type III diffractometer (Rigaku, Tokyo, Japan) equipped with Cross Beam Optics (CBO) and $\mathrm{Cu} \mathrm{K} \alpha$ radiation. The samples were scanned with 2 Theta $(2 \theta)$ values between $20^{\circ}$ and $55^{\circ}$ carried out in parallel beam mode with a fixed incident angle of $10^{\circ}$ and a $0.11^{\circ}$ parallel slit analyzer.

The surface morphology of each coating was observed under a scanning electron microscope (SEM, Camscan Series 2, Obducat CamScan Ltd., Cambridgeshire, United Kingdom) at $20 \mathrm{kV}$. Prior to SEM the samples were sputter coated with gold (K550, Emitech, West Sussex, UK) for $30 \mathrm{~s}$.

Energy-dispersive X-ray spectroscopy (EDX) was carried out with an INCA PentalFETx3 (Oxford Instruments, Tubney Woods, UK) mounted to a SEM Supra40 (Carl Zeiss AG, Oberkochen, Germany). EDX analysis was done from top views and fracture surfaces (EpoFix, Struers GmbH, Willich, Germany) of the different coatings. The samples were sputter-coated with carbon for $9 \mathrm{~s}$ with a Carbon Coater 108 (Cressington, Watford, UK).

The average surface roughness (Sa) was achieved with an optical profilometer $(\mathrm{P} 1 \mu 2300$, Sensofar, Terassa, Spain) by scanning an area of $477 \times 636 \mu \mathrm{m}^{2}$ according to ISO 25178.

Mechanical strength of adhesion between coating and substrate was evaluated using a hardness tester (PH5800, BYK-Gardner GmbH, Geretsried, Germany) with a pencil-shaped bovine femur (Vickers hardness $89.8 \pm 5.2 \mathrm{HV}$ 0.2). The test were carried out according to ISO 15184 with a constant load of $7.5 \mathrm{~N}$, a velocity of $1 \mathrm{~mm} / \mathrm{s}$ and a scratch length of $12 \mathrm{~mm}$. Bone leftovers on the sample surface were burned out at $1400^{\circ} \mathrm{C}$, and the sample surface was observed by SEM.

Biaxial flexural strength of coated specimens was tested with the ball on three balls (B3B) test according to Börger et $\mathrm{al}^{28}$ using a universal testing machine (Zwick/Roell Z005, Ulm, Germany). Each specimen was centrally placed on three metal balls ( $4 \mathrm{~mm}$ radius) and loaded with a fourth ball with a constant speed of $0.5 \mathrm{~mm} / \mathrm{min}$. The coated surface was oriented to the tension side and 30 samples for each coating composition were analyzed. The maximum applied load was recorded and the biaxial flexural strength was calculated as described elsewhere. ${ }^{28}$ Fracture surfaces of the B3B specimens were observed with SEM after B3B test to analyze the coating-substrate interface.

\section{Insertion and dissection of coated zirconia dental implants}

The coated zirconia screws $(n=20)$ were divided into two groups and inserted into predrilled holes of either fresh bovine rip bones or into biomechanical test blocks (solid rigid polyurethane foams, $40 \mathrm{pcf}=0.64 \mathrm{~g} / \mathrm{cc}$, Sawbones Europe AB, Malmö, Sweden). The insertion was carried out with drilling and insertion tools from the similarly macro-designed implant system (BEGO Semados ${ }^{\circledR}$ RI; BEGO Implant Systems, Bremen, Germany) and performed according to the clinical protocols and manufacturer's recommendations. Coating morphology and stability were observed by SEM after careful dissection of implants.

\section{Dissolution behavior}

In order to characterize the dissolution behavior of all studied coatings, the specimens $(n=4)$ were immersed in $1 \mathrm{ml}$ Tris- $\mathrm{HCl}$ buffer over a period of 3 weeks. The Tris$\mathrm{HCl}$ buffer solution was prepared by dissolving $13.25 \mathrm{~g}$ of Tris(hydroxymethyl)aminomethane in $500 \mathrm{ml}$ doubledeionized water and buffered at $\mathrm{pH} 7.4$ with $1 \mathrm{M}$ hydrochloric acid $(\mathrm{HCl})$ at $37^{\circ} \mathrm{C}$ according to ISO 10993-14. The test was carried out in an incubator at $37^{\circ} \mathrm{C}$ (Inkubator 1000, Heidolph, Schwabach, Germany) with an integrated shaker $(160 \mathrm{r} / \mathrm{min}$, Unimax 1010 , Heidolph). The sampling was done at 12 different time points by renewing the supernatant. At each sampling time the ion concentration of calcium $\left(\mathrm{Ca}^{2+}\right)$ and magnesium in the supernatant was measured photometrically. The $\mathrm{Ca}^{2+}$ ion concentration was determined using the ortho-cresolphthalein complexone method in accordance to manufacturer's instruction (Fluitest $\mathrm{Ca}$ CPC, 
Analyticon Biotechnologies AG, Lichtenfels, Germany) at $578 \mathrm{~nm}$ (Multiscan GO, Thermo Scientific, Schwerte, Germany). $\mathrm{Mg}^{2+}$ ion concentration was analyzed with xylidyl blue according to manufacturer's instruction (Fluitest MG XB, Analyticon Biotechnologies AG) at $546 \mathrm{~nm}$. The released $\mathrm{Ca}^{2+}$ and $\mathrm{Mg}^{2+}$ ion concentration was used to calculate the cumulative dissolution kinetics.

\section{Immersion in SBF}

Conventional simulated body fluid (cSBF) containing ion concentrations similar to blood plasma was prepared as previously described ${ }^{29}$ and according to ISO 23317. The following salts $\mathrm{NaCl}, \mathrm{NaHCO}_{3}, \mathrm{KCl}$, $\mathrm{K}_{2} \mathrm{HPO}_{4} \cdot 3 \mathrm{H}_{2} \mathrm{O}, \mathrm{MgCl}_{2} \cdot 6 \mathrm{H}_{2} \mathrm{O}, \mathrm{CaCl}_{2}$ and $\mathrm{Na}_{2} \mathrm{SO}_{4}$ were dissolved in double distilled water and buffered at $\mathrm{pH} 7.4$ with Tris- $\mathrm{HCl}$. The specimens were soaked in $40 \mathrm{ml}$ of $\mathrm{SBF}$ solution at $37^{\circ} \mathrm{C}$ under static conditions in a climate chamber (KBF 115, Binder, Tuttlingen, Germany) for 21 days. After immersion, the samples were gently rinsed with deionized water and dried at room temperature prior analysis by SEM (Carl Zeiss AG, Oberkochen, Germany).

\section{Cell testing}

Prior to in vitro investigations all specimens were heat sterilized at $200^{\circ} \mathrm{C}$ for $2 \mathrm{~h}$. The different coatings were compared with Thermanox ${ }^{\circledR}$ coverslips (diameter $=15 \mathrm{~mm}$, Thermo Fisher Scientific Inc., Bonn, Germany) as reference material.

$\mathrm{HOB}$ cells were obtained from Provitro $\mathrm{GmbH}$ (Berlin, Germany) and routinely cultured in Dulbecco's modified Eagle's minimal essential medium (D-MEM, Gibco, Life Technologies GmbH, Darmstadt, Germany) supplied with $10 \%$ heat-inactivated fetal calf serum (FCS) and 1\% antibiotic-antimycotic (Gibco) under standard conditions $\left(37^{\circ} \mathrm{C}, 9.3 \% \mathrm{CO}_{2}\right.$ and $95 \%$ relative humidity). The samples were placed in 24 -well multidishes and the cells were seeded onto the samples at $2 \times 10^{4}$ cells $/ \mathrm{ml}$. The cell culture medium was changed every two days.

The cell metabolic activity was determined using a colorimetric water-soluble tetrazolium salt (WST-1, Roche Diagnostics GmbH, Mannheim, Germany), which is enzymatically cleaved to formazan only by living cells. The WST-1 reagent was added to each well after medium change at days 1, 4, 7 and 9 of culture. The absorbance was read after $2.5 \mathrm{~h}$ of incubation using a microplate reader at $450 \mathrm{~nm}$ (Chameleon, HIDEX, Turku, Finland). Six specimens for each kind of coating and day were used.

Cell number, alkaline phosphatase activity (ALP) and protein content were determined after 4, 7 and 9 days of culture. Cells were detached using trypsin/ethylenediaminetetraacetic acid (EDTA) $(0.25 \%$ trypsin $/ 0.02 \%$ EDTA), concentrated by centrifugation at $14,000 \mathrm{rcf}$ for $5 \mathrm{~min}$ and lysed in 1\% Triton X-100 in $0.9 \% \mathrm{NaCl}$ using five specimen for each kind of coating and day.

The cell number was quantified by measuring the DNA content using the Quant-iT ${ }^{\text {TM }}$ PicoGreen ${ }^{\circledR}$ dsDNA Kit (Life Technologies). An aliquot of the cell lysate was diluted with $1 \times$ TE buffer $(10 \mathrm{mM}$ Tris- $\mathrm{HCl}$, 1 mM EDTA, pH 7.5) prior addition of PicoGreen working solution. The sample fluorescence was measured after an incubation of $5 \mathrm{~min}$ in the dark at an excitation wavelength of $485 \mathrm{~nm}$ and an emission wavelength of $535 \mathrm{~nm}$ using a plate reader (Chameleon, HIDEX). The DNA concentration was correlated with the cell number using a calibration curve with defined cell number.

For determination of ALP activity an aliquot of the cell lysate was added to ALP substrate buffer, containing $6 \mathrm{mM}$ p-nitrophenyl phosphate in $0.1 \mathrm{M}$ glycine, $1 \mathrm{mM} \mathrm{MgCl} 2,0.1 \mathrm{mM} \mathrm{ZnCl} 2$ and incubated at $37^{\circ} \mathrm{C}$ for $30 \mathrm{~min}$. The reaction was stopped with $1 \mathrm{M} \mathrm{NaOH}$ and the absorbance of released $p$-nitrophenol was read at $405 \mathrm{~nm}$ on a plate reader. A standard curve was generated with different concentrations of $p$-nitrophenol. The ALP activity was normalized to protein content, which was quantified with the Pierce ${ }^{\circledR}$ BCA Protein Assay Kit (Thermo Scientific). An aliquot of the cell lysate was incubated with working reagent at $37^{\circ} \mathrm{C}$ for $30 \mathrm{~min}$ and afterwards measured at a wavelength of $570 \mathrm{~nm}$. For the standard curve serial dilutions of bovine serum albumin (BSA) were made.

Cell morphology and growth were evaluated at days 1,4 and 7 of culture by immunofluorescence staining. The samples $(n=3)$ were rinsed with $37^{\circ} \mathrm{C}$ PBS and fixed for $15 \mathrm{~min}$ at room temperature in $4 \%$ paraformaldehyde (PFA) (Riedel-de Haën, Seelze, Germany). After fixation cells were washed with PBS, permeabilized with $0.5 \%$ Triton X-100 for $3 \mathrm{~min}$ and washed again with PBS. Cell nuclei were stained with 4,6-diamidino-2-phenylindole (DAPI, 1:2500) and the cytoskeleton with AlexaFluor ${ }^{\circledR} 488$-Phalloidin (1:100, Life Technologies) for $45 \mathrm{~min}$ at room temperature in the dark. Afterwards, the cells were rinsed with PBS and imaged using an AX-10 fluorescence microscope (Axio Vision Imager M.1, Carl Zeiss AG, Jena, Germany).

\section{Statistical analysis}

Statistical analyses were assessed by one-way ANOVA followed by Tukey's test (Minitab 16, Minitab Inc., Pennsylvania, USA) to determine statistical significance between different coated groups. A $p$ value $<0.05$ was considered to indicate a statistically significant difference. 

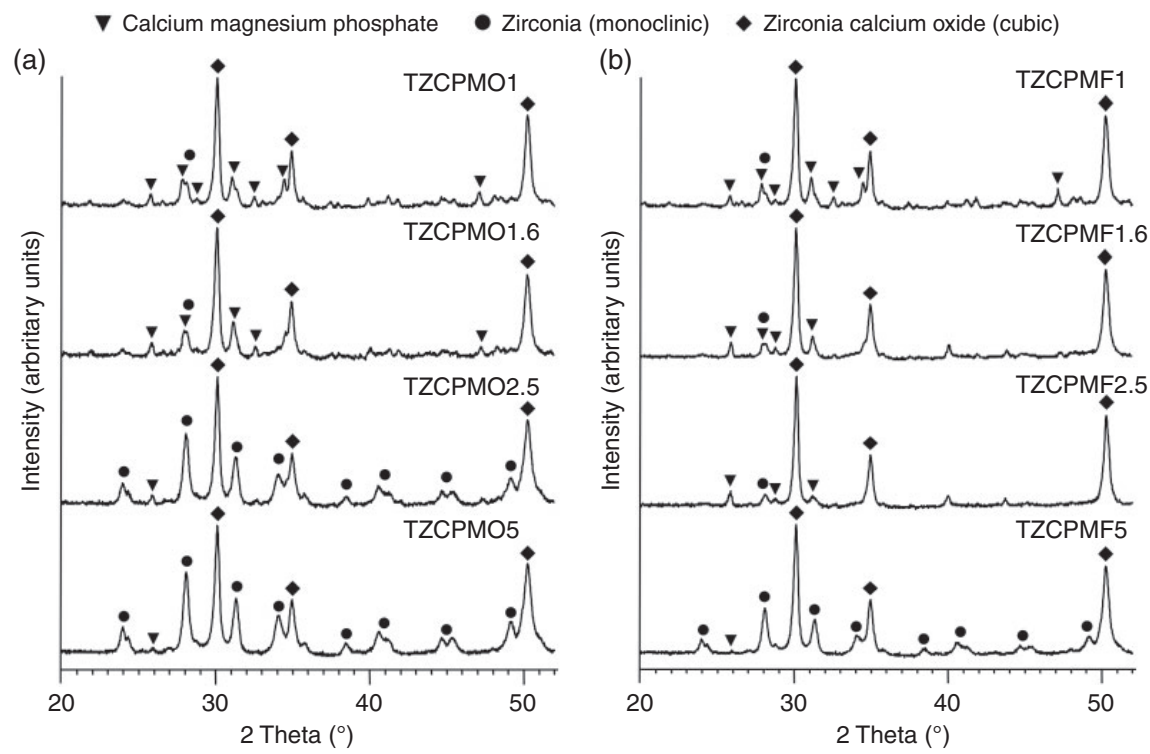

Figure I. GIXRD patterns of the different mixed coatings with $\mathrm{MgO}$ (a) and $\mathrm{MgF}_{2}$ addition (b) after heat treatment at $\mathrm{I} 500^{\circ} \mathrm{C}$.

\section{Results}

\section{Composition and morphology of coatings}

The GIXRD profiles of the deposited and sintered coatings with $\mathrm{Mg}$ addition by $\mathrm{MgO}$ or $\mathrm{MgF}_{2}$ are shown in Figure 1. The composition of the coatings consisted of equal TZ and CP contents, however, the amount of $\mathrm{Mg}$ varied between 1 till $5 \mathrm{wt} \%$. The diffraction peaks for both $\mathrm{Mg}$ sources are mainly assigned to cubic and monoclinic zirconia, with the latter gaining in intensity with increasing $\mathrm{Mg}$-concentration. In addition, a new calcium magnesium phosphate phase $(\mathrm{CaMgP})$ is detected after heat treatment, which intensity decreases with increasing Mg-content. Coatings with the same Mg-content show equal diffractograms, except for the case of $2.5 \mathrm{wt} \% \mathrm{Mg}$-addition.

Figure 2(a) to (h) shows the typical morphologies of mixed coatings with different magnesium addition, TZCP without magnesium was included as reference material (Figure 2i). All coatings displayed an undulated, porous and rough surface microstructure, which is suitable for bone implants. The addition of 1 or $1.6 \mathrm{wt} \%$ did not influence the coating morphology, whereas coatings with a concentration of $2.5 \mathrm{wt} \% \mathrm{Mg}$ showed an irregular, inhomogeneous granular structure independent of the $\mathrm{Mg}$-source. A Mg content of $5 \mathrm{wt} \%$ in turn resulted only in a slight morphology change. However, the shape of the grains differed and was more irregular in comparison with the reference coating. Moreover, the addition of $\mathrm{Mg}$ had no significant influence on the average surface roughness, which was around $4 \mu \mathrm{m}$ (Table 2). Porosity and pore size were predominantly not affected by $\mathrm{Mg}$ addition except for samples TZCPMO2.5 and TZCPMF2.5 due to changed coating morphology.

EDX point analyses (Figure $2 \mathrm{j}$ and $\mathrm{k}$ ) showed that the bright gray areas contain zirconium and a small amount of calcium, while the dark gray areas contain magnesium, calcium and phosphate. These findings are in accordance with the GIXRD data.

\section{Mechanical stability and coating adhesion}

The biaxial flexural strength values of different coated samples measured by B3B are displayed in Figure 3(a) and the mean strength values of investigated specimens are summarized in Table 2. The highest flexural strength of about $1000 \mathrm{MPa}$ was found for TZCP and TZCPMO1. At other Mg concentrations and independent of the $\mathrm{Mg}$ source, the specimen showed a lower strength. It can be noticed that the strength-decreasing effect is more pronounced with addition of $\mathrm{MgF}_{2}$ than $\mathrm{MgO}$. Within the $\mathrm{Mg}$-containing coatings the tendency of decreasing strength with increasing $\mathrm{Mg}$ content can be clearly seen, except for samples with $5 \mathrm{wt} \% \mathrm{Mg}$ addition.

Additional investigations of fracture surfaces (Figure 3b) corroborated these B3B results. Coatings with a smooth and continuous morphology along the interbonding show higher strength values in comparison to specimens with a distinct interface between substrate and coating. The thickness of the interface layer increased with the amount of $\mathrm{Mg}$ in the coating mixture, and decreased again at $5 \mathrm{wt} \% \mathrm{Mg}$. EDX analysis of the interfacial layer revealed zirconium and calcium peaks.

The coating-substrate adhesion plays a crucial role in determining the usability and reliability of coated 

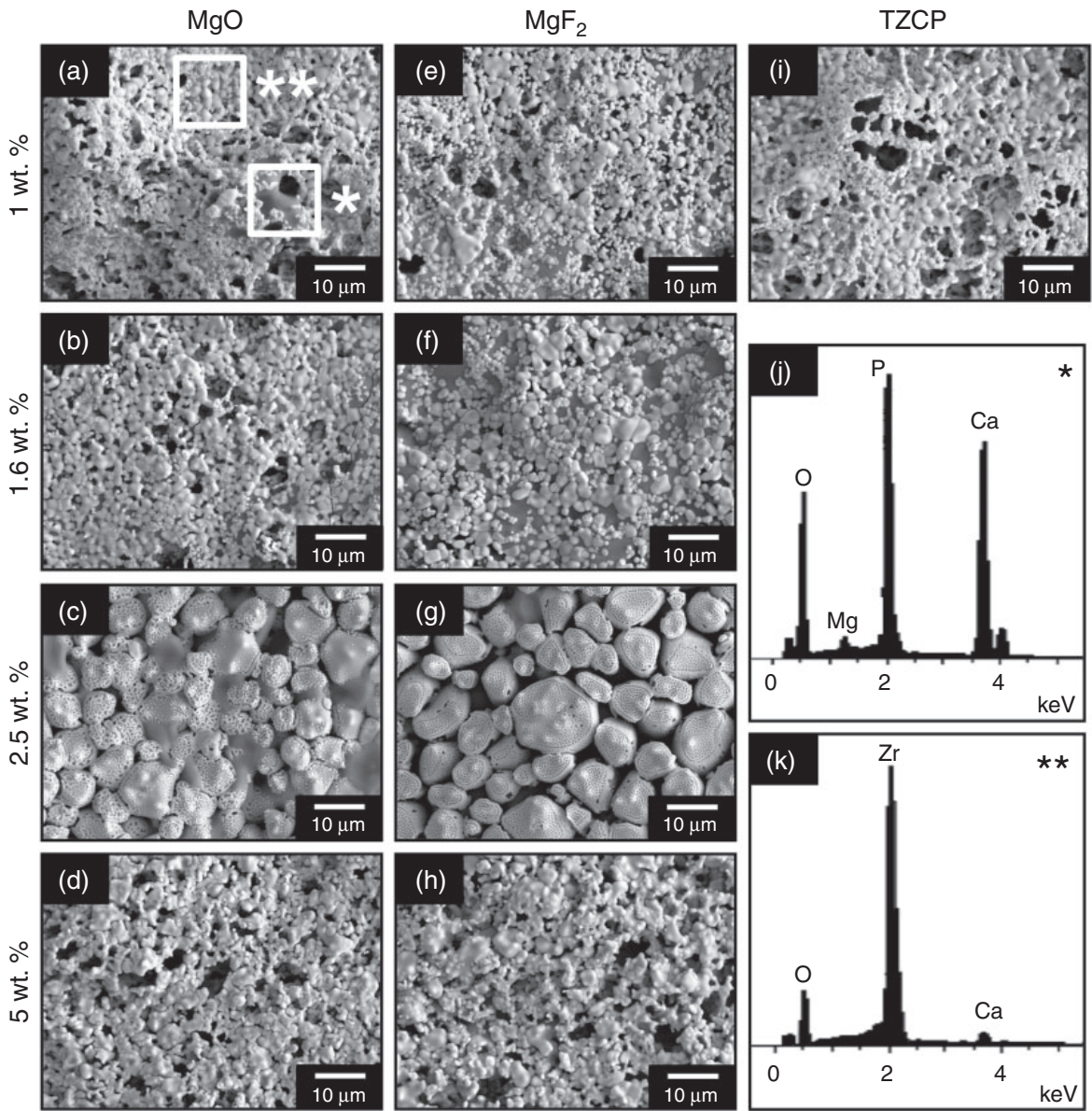

Figure 2. Surface morphologies of sprayed coatings on TZ obtained by WPS after heat treatment at $1500^{\circ} \mathrm{C}$. (a) $-(\mathrm{d})$ : coatings with $\mathrm{MgO}$ addition, (e)-(h): coatings with $\mathrm{MgF}_{2}$ addition, (i): reference coating without magnesium addition. (j)-(k): EDX point analysis of bright gray grains $\left(^{*}\right)$ and dark gray areas $\left(^{* *}\right)$ of sample (a) indicate the typical major elements of calcium magnesium phosphate and cubic zirconia, respectively.

implants for dental and orthopedic applications. ${ }^{30}$ In this study, the coating adhesion was investigated by a scratch test and via insertion experiments with coated zirconia screw implants. Figure 4 shows representative top views of the sample surface before (a) to (c) and after (d) to (e) scratch test carried out with a sharpened bovine femur, where the dashed black lines correspond to the scratch path. At a constant load of $7.5 \mathrm{~N}$ the coatings with $1 \mathrm{wt} \% \mathrm{Mg}$ addition maintained their integrity indicating a strong interbonding between coating and substrate. No difference compared to the reference was observed, suggesting no adverse effect of $\mathrm{Mg}$ on coating adhesion.

Insertion experiments with screw implants were additionally carried out to investigate the stability and adhesion of coatings on curved parts. The homogenously coated implants that show the same surface morphology compared to coatings obtained on planar discs (Figure 5a) were carefully dissected after insertion into Sawbone and bovine rip bone using a clinical protocol (Figure 5b). These insertions experiments with coated zirconia implants confirmed the scratch test results, indicating a firm adhesion of the coating even under load application. Images of the other investigated coatings are not shown due to same achieved results; an increase in $\mathrm{Mg}$-content did not alter coating adhesion and stability.

\section{In vitro bioactivity assessment}

The cumulative calcium and magnesium ion release in Tris- $\mathrm{HCl}$ buffer over a period of 3 weeks is shown in Figure 6. During the first 4 days of immersion the ionic concentration of $\mathrm{Ca}^{2+}$ and $\mathrm{Mg}^{2+}$ increased rapidly followed by gradual increase on the following days. This behavior could be observed for all coatings and both investigated ions. Compared to the reference sample TZCP, Mg-addition led to a diminished $\mathrm{Ca}^{2+}$ release 


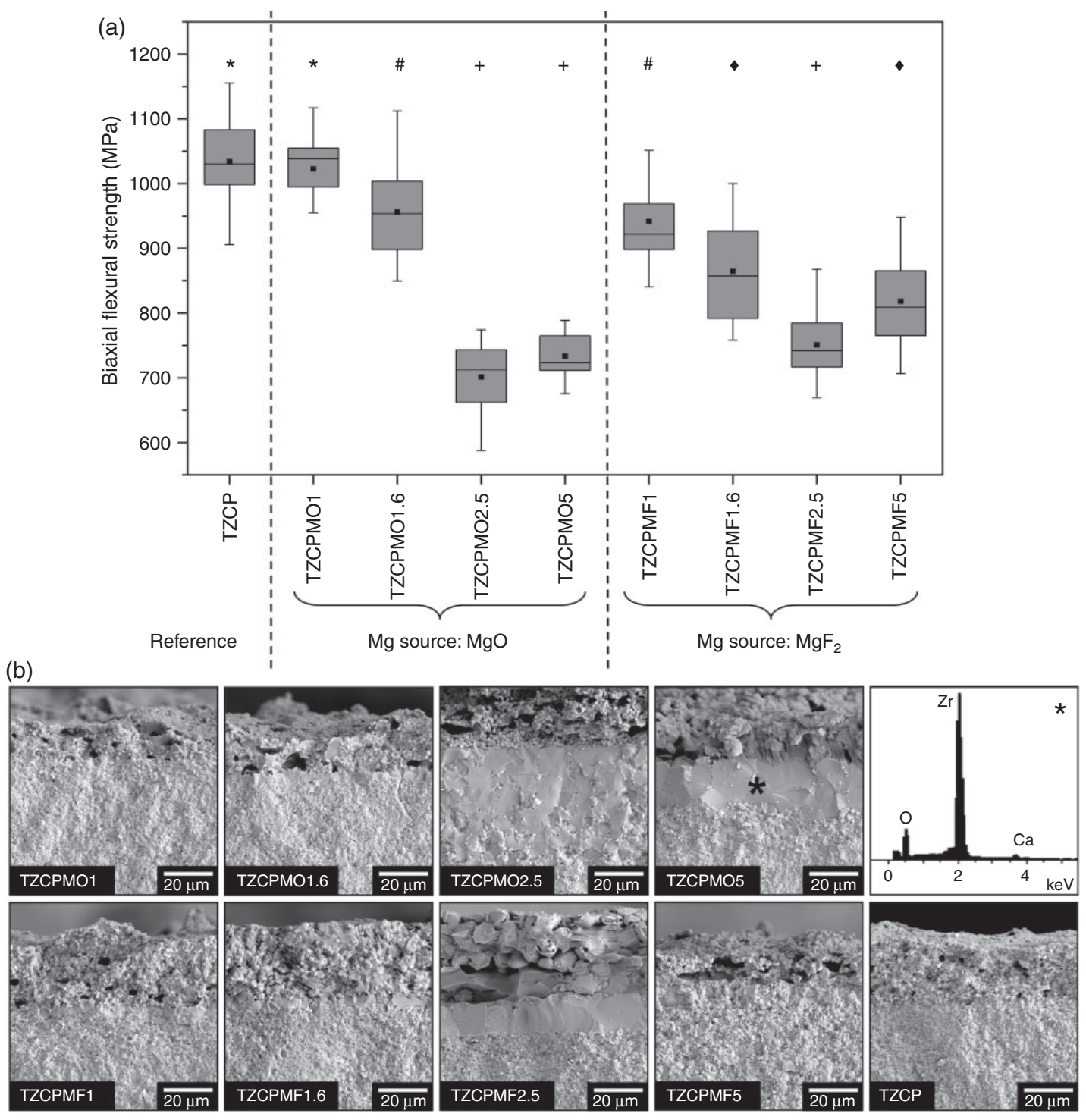

Figure 3. Mechanical strength behavior of various coated samples determined via B3B. (a) Box plot diagram of the biaxial flexural strength. The black rectangle marks the mean value and the horizontal line the median. Columns with distinct symbols are significantly

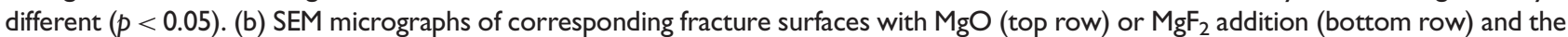
reference sample without magnesium (TZCP). EDX point analysis $\left(^{*}\right)$ indicates typical peaks for zirconium and calcium in the interface layer.

Table 2. Surface roughness, coating thickness and biaxial flexural strength.

\begin{tabular}{llll}
\hline Sample & Roughness Sa $(\mu \mathrm{m})$ & Coating thickness $(\mu \mathrm{m})$ & Flexural strength $(\mathrm{MPa})$ \\
\hline TZCP & $4.79 \pm 0.39$ & $22.2 \pm 1.2$ & $1034 \pm 59$ \\
TZCPMOI & $3.55 \pm 0.38$ & $13.9 \pm 2.3$ & $1023 \pm 75$ \\
TZCPMOI.6 & $3.62 \pm 0.53$ & $14.2 \pm 2.1$ & $956 \pm 68$ \\
TZCPMO2.5 & $3.56 \pm 0.49$ & $22.6 \pm 2.1$ & $701 \pm 54$ \\
TZCPMO5 & $3.59 \pm 0.45$ & $16.7 \pm 5.7$ & $734 \pm 32$ \\
TZCPMFI & $3.90 \pm 0.61$ & $26.0 \pm 1.7$ & $942 \pm 76$ \\
TZCPMFI.6 & $3.93 \pm 0.48$ & $27.1 \pm 2.6$ & $865 \pm 71$ \\
TZCPMF2.5 & $3.63 \pm 0.29$ & $29.3 \pm 4.1$ & $751 \pm 44$ \\
TZCPMF5 & $4.03 \pm 0.55$ & $13.3 \pm 2.2$ & $818 \pm 63$ \\
\hline
\end{tabular}

TZCP: zirconia-calcium phosphate. 

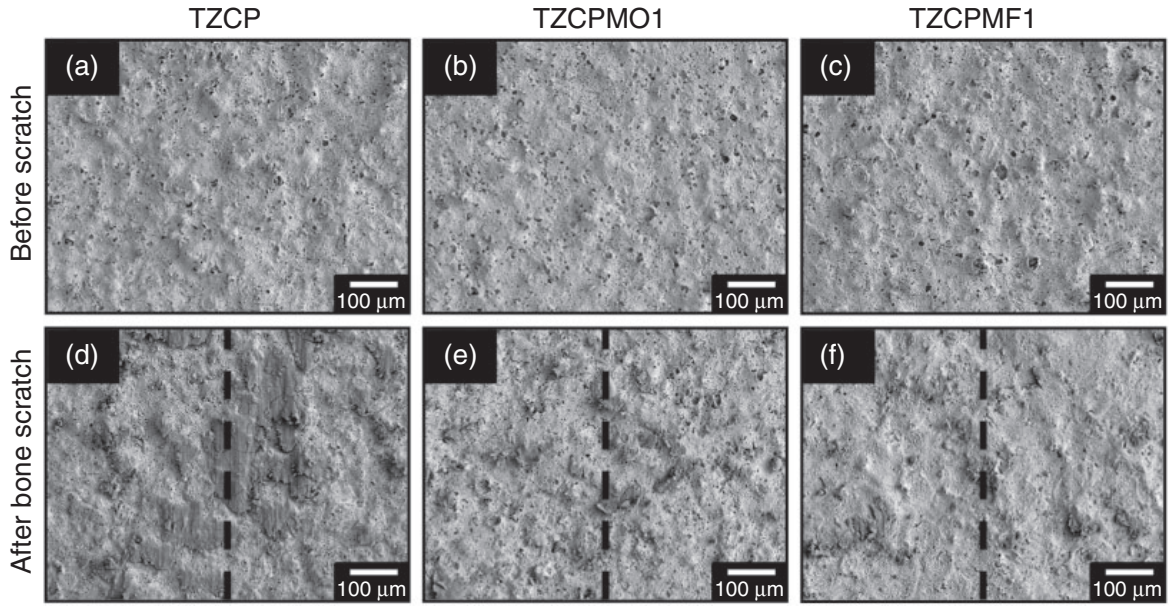

Figure 4. SEM micrographs of the coating morphology before (top row) and after bone scratch (bottom row). The black dashed lines represent the scratches.
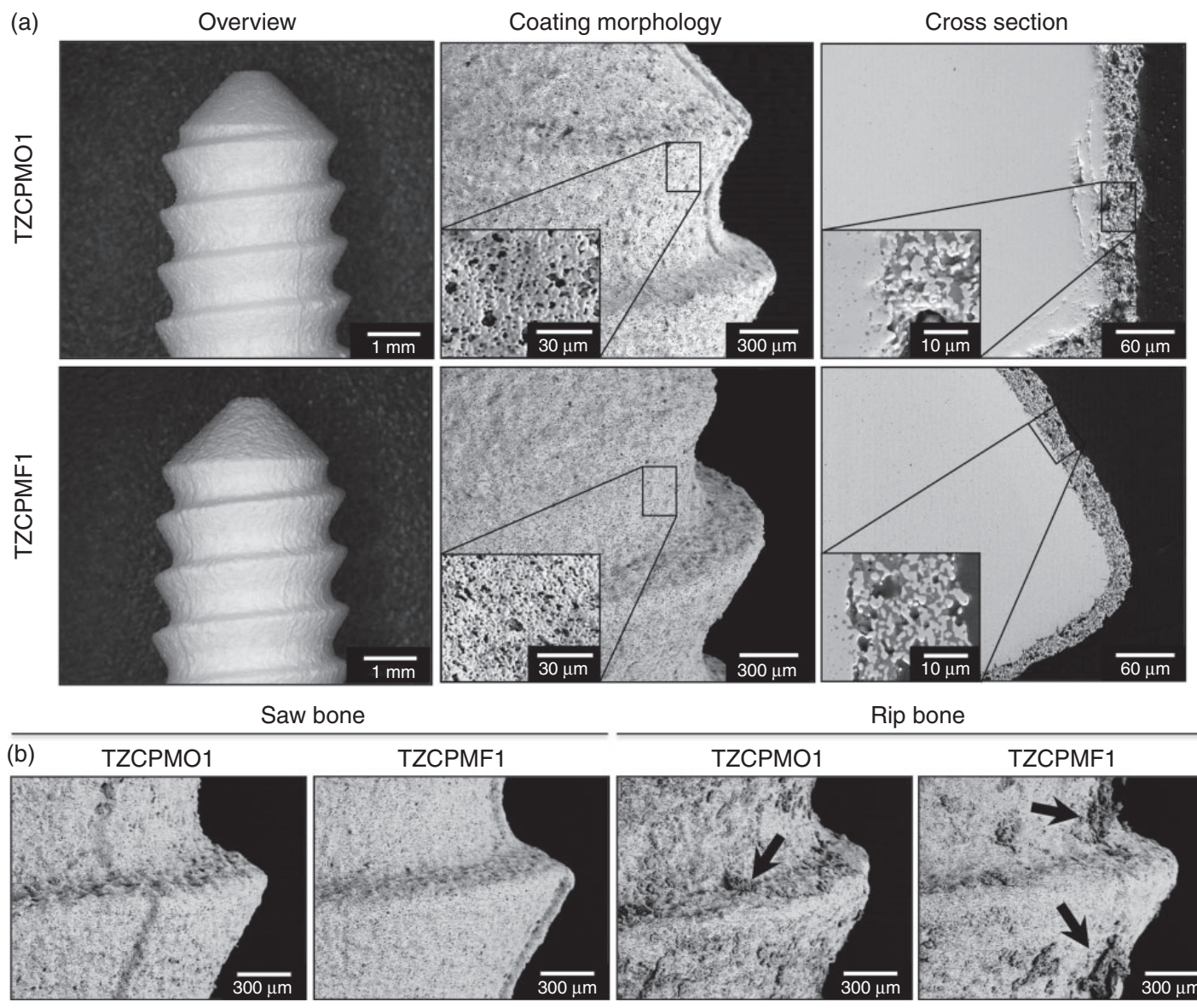

Rip bone

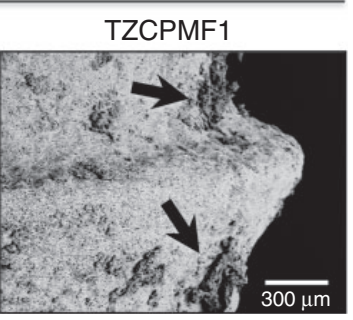

Figure 5. (a) Implant overview, coating detail and cross section of zirconia implants coated with mixed coatings via WPS after sintering at $1500^{\circ} \mathrm{C}: \mathrm{MgO}$ (top row) and $\mathrm{MgF}_{2}$ (bottom row) addition. (b) Implant coating morphology after insertion and dissection of Sawbone (left) and bovine rip bone (right) of mixed coating with $\mathrm{I} w \mathrm{w} \% \mathrm{MgO}$ and $\mathrm{MgF}_{2}$ addition. Arrows depict bone residues after burn out. 

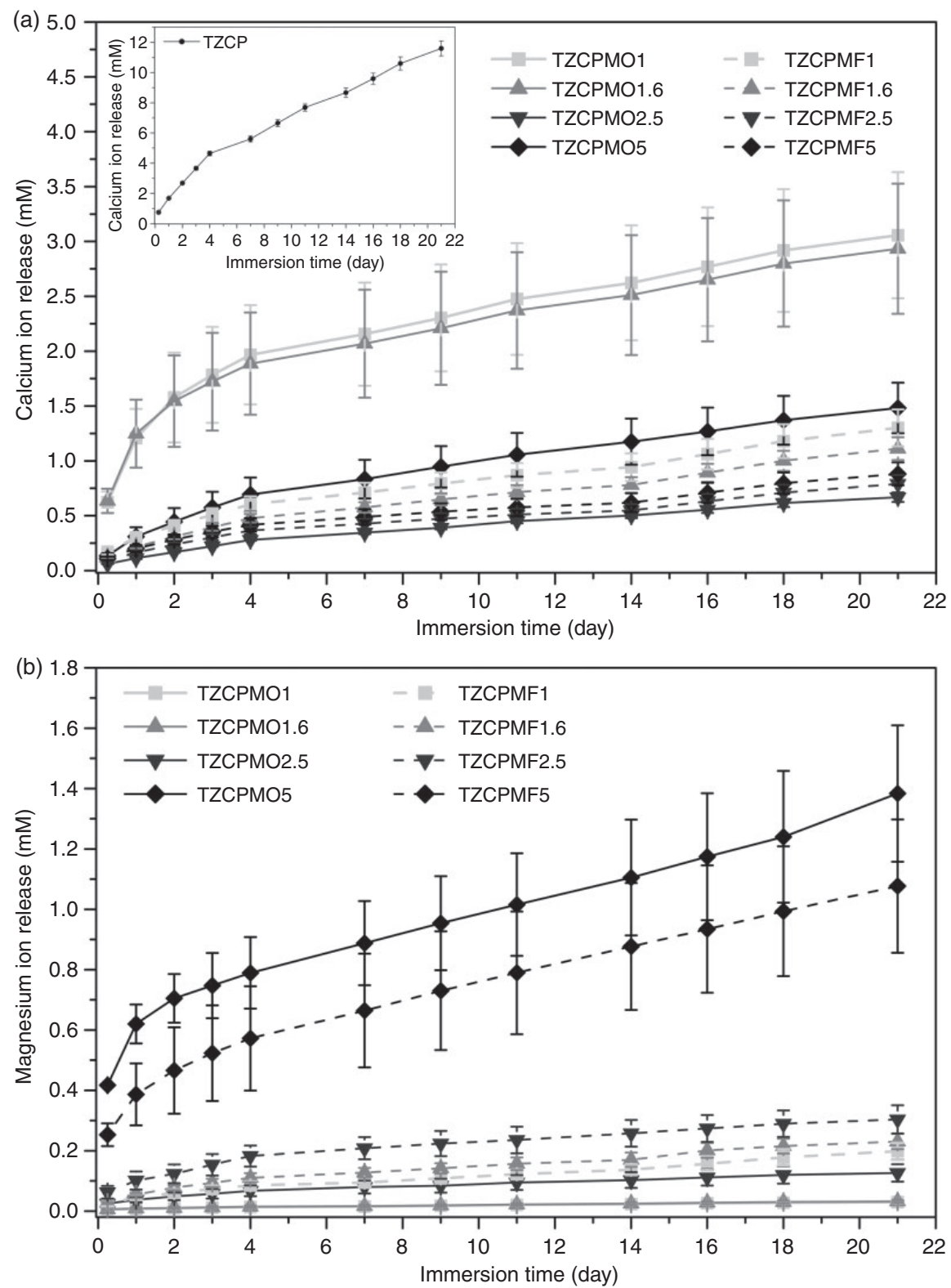

Figure 6. Dissolution behavior of mixed coatings sintered at $1500^{\circ} \mathrm{C}$ after immersion at $\mathrm{pH} 7.4$ for a period of 21 days as a function of immersion time: calcium ion release (a) compared to the calcium ion release of a mixed coating without magnesium, and magnesium ion release (b) of coatings with $\mathrm{MgO}$ (square) and $\mathrm{MgF}_{2}$ (triangle) addition.

around $75 \%$. It can also be observed that $\mathrm{Ca}^{2+}$ release is influenced by the amount of $\mathrm{Mg}$-addition, the higher the amount of $\mathrm{Mg}$ the lower the $\mathrm{Ca}^{2+}$ release. Furthermore, $\mathrm{MgF}_{2}$ significantly reduced $\mathrm{Ca}^{2+}$ release already at lower concentrations in comparison to $\mathrm{MgO}$. For $\mathrm{Mg}^{2+}$ release the opposite behavior was observed, higher $\mathrm{Mg}^{2+}$ concentrations were found in the supernatant with increasing content of $\mathrm{Mg}$ in the coating. At the same time there is no significant difference in $\mathrm{Mg}^{2+}$ release between coatings with comparable amounts of $\mathrm{MgO}$ or $\mathrm{MgF}_{2}$ addition.
Figure 7 shows SEM images of Mg-coatings after soaking in SBF solution for 21 days. After immersion in SBF only samples TZCPM1, TZCPM1.6 and TZCMF1.6 exhibited a partial covering of the surface with a new mineral layer, which possessed the typical globular morphology of apatite precipitates. Within these samples TZCPMO1.6 showed the highest formation ability. A higher magnification of this new layer evidenced the detailed layer structure (inset in Figure $7 b)$. On the other sample surfaces no precipitation was observed. 

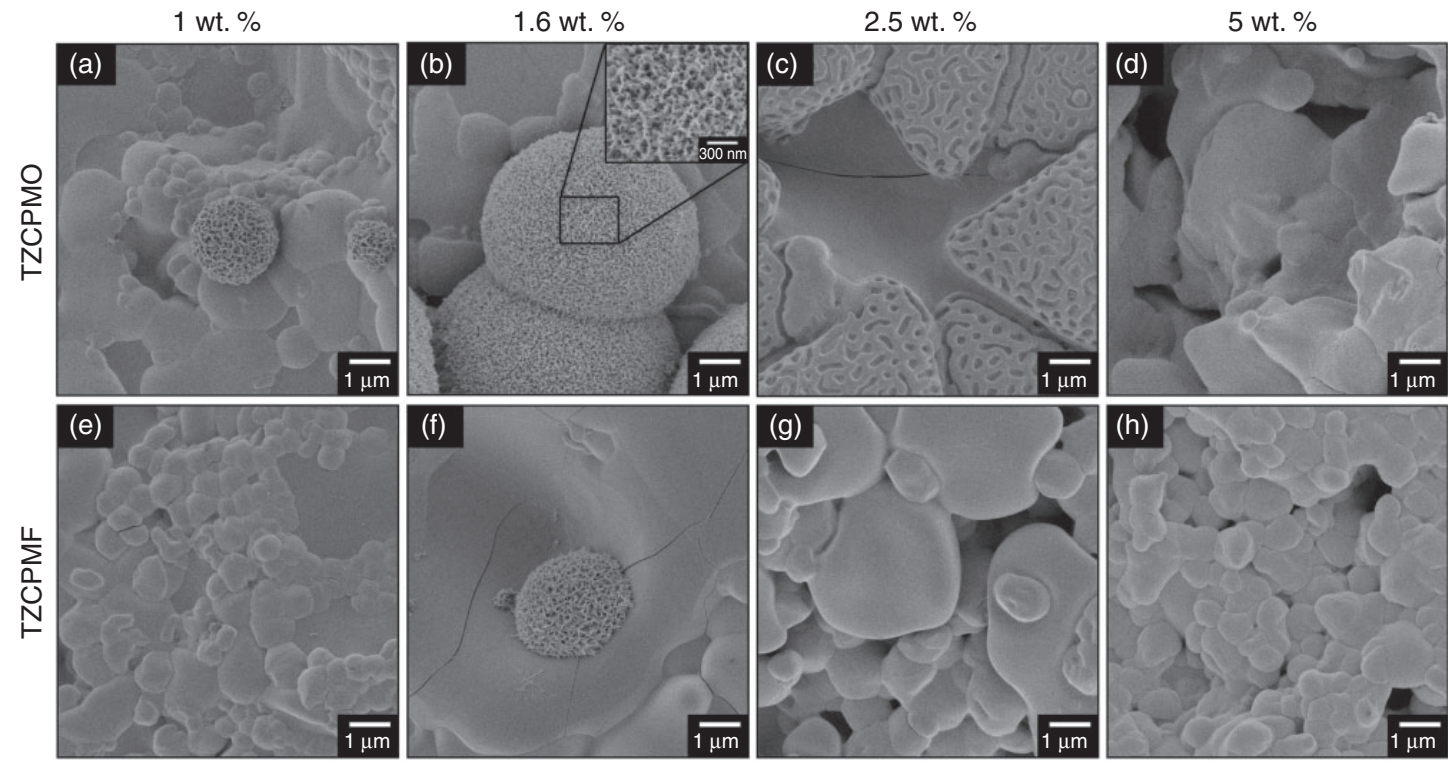

Figure 7. SEM micrographs of mixed coatings with $\mathrm{MgO}$ (top) and $\mathrm{MgF}_{2}$ (bottom) addition after immersion in $\mathrm{SBF}$ for $2 \mathrm{I}$ days. A newly formed layer on the tested coatings with the typical apatite structure (inset) was only observed on TZCPMOI, TZCPMOI.6 and TZCPMFI.6.

\section{In vitro biological characterization}

In this study we chose HOBs as an in vitro model. Cell viability, proliferation, differentiation and morphology of $\mathrm{HOB}$ cultured on different samples were investigated for 1, 4, 7 and 9 days, respectively. For in vitro tests, samples were selected with the lowest impact on strength and the ability of mineral layer formation on the surface. We, therefore, consequently chose coatings with $1 \mathrm{wt} \%$ and $1.6 \mathrm{wt} \% \mathrm{Mg}$ addition from both $\mathrm{Mg}$ sources $\mathrm{MgO}$ and $\mathrm{MgF}_{2}$; TZCP and Thermanox ${ }^{\circledR}$ were used as reference samples.

WST tests revealed the metabolic activity of $\mathrm{HOB}$ on all tested specimens. The constant increase of formazan over 9 days of culture seen on all materials (Figure 8a) indicated a steady cellular proliferation. Thermanox ${ }^{\circledR}$ exhibited almost on all sampling days the highest metabolic activity, but it can also be noticed that the $\mathrm{Mg}$ containing coatings converged with Thermanox ${ }^{\circledR}$ after 9 days of culture and the cells showed the same metabolic activity, whereas TZCP consistently exhibited the lowest activity.

Cell proliferation process was monitored by quantification of cell number (Figure $8 \mathrm{~b}$ ) and protein amount (Figure 8c). The number of cells and protein content increased with culture time on all studied specimens. Within each cell culture day, the proliferation on Thermanox $^{\circledR}$ is generally higher than or similar to some Mg-containing coatings. The reference TZCP displayed the lowest cell proliferation on all sampling days.
The cell differentiation was evaluated as an early differentiation marker for osteoblasts (Figure 8d). The ALP activity increased on all samples during culture duration, and apparently the enzymatic activity was reduced on TZCP, whereas a significantly increased activity was observed on Thermanox ${ }^{\circledR}$. Among the coated samples TZCPMO1.6 showed a significantly higher ALP activity after 9 days of culture.

Figure 9 shows the cell growth behavior, spreading and morphology on coatings with 1 and $1.6 \mathrm{wt} \% \mathrm{Mg}-$ addition, as well as on TZCP and Thermanox ${ }^{\circledR}$. At day 1 most of the cells possessed a polygonal shape with cellular protrusions. On TZCP numerous cells displayed a round morphology, whereas on Thermanox ${ }^{\circledR}$ the cells were flat and spread more extensively. Within the Mg-containing coatings, the cells exhibited a similar morphology that was comparable to Thermanox $^{\circledR}$. After 4 days of culture the cells were well flattened and spread over the sample surfaces of all coatings. Cell proliferation on TZCP was less pronounced in comparison to the other investigated specimens, on Thermanox $^{\circledR}$ the opposite was observed. Within the Mg-containing coatings the cell number was slightly higher on samples with $1.6 \mathrm{wt} \% \mathrm{Mg}$-addition. At day 7 of culture, the same behavior is further illustrated. The cells grew to confluence on all Mg-containing coatings and Thermanox ${ }^{\circledR}$, except on TZCP where still vacancies were observed, confirming our WST and cell number assay results.

In summary it can be said that the highest viability, cell number and ALP activity was found on 

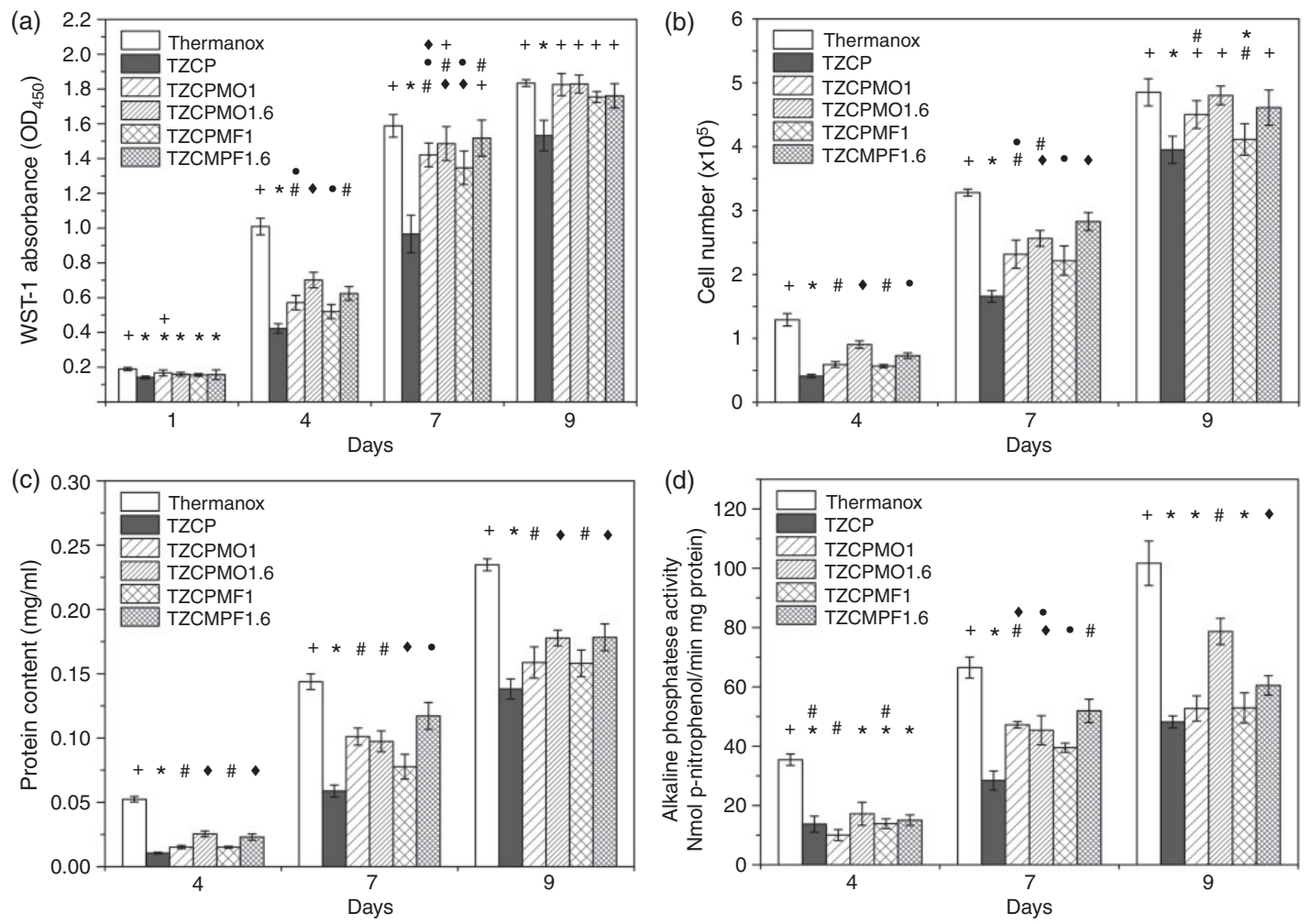

Figure 8. (a) Quantification of metabolic activity, (b) cell proliferation, (c) protein content and (d) ALP activity of HOB cultured on different coated samples and on Thermanox ${ }^{\circledR}$ over a culture period of 9 days. The symbols above the columns mark the significance level. Significantly different values are characterized by different symbols $(p<0.05)$.

Thermanox ${ }^{\circledR}$ and the lowest in contrast on the reference TZCP. However, the appearance and proliferation of cells on $\mathrm{Mg}$-containing samples was comparable with Thermanox ${ }^{\circledR}$. Within the Mg-containing coatings, the tendency of slightly better results for samples with $1.6 \mathrm{wt} \% \mathrm{Mg}$-addition was detected.

\section{Discussion}

In this study, the effects of varying $\mathrm{Mg}$-contents, added to TZCP coatings and deposited on zirconia substrates, were investigated. Our approach aimed at mimicking both the natural topography and chemistry of bone tissue to create a conducive environment for improved bone ingrowth, without changing the bulk material properties of the implant. The coatings were applied with the WPS technique, which suitability was already shown in previous works. ${ }^{19,31}$ Since bone is a porous material, the obtained porous coatings represent a more natural morphology with varying pore sizes in order to facilitate cell anchoring and thus bone ingrowth. Moreover, Mg-addition was considered to increase the coating biocompatibility due to a more similar bone composition. The sintering step after coating led on the one hand to a sufficient bonding between coating and substrate, but also induced on the other hand phase decomposition caused by the high sintering temperature. In addition, to the already known transformation of tetragonal to cubic zirconia caused by $\mathrm{CaO}$ diffusion of the $\mathrm{CP}$ decomposition, the addition of $\mathrm{Mg}$ favored the formation of a new $\mathrm{CaMgP}$ phase. The intensity of the $\mathrm{CaMgP}$ peaks decreased with increasing $\mathrm{Mg}$ content, whereas the intensity of monoclinic zirconia increased simultaneously. This effect is more pronounced with the addition of $\mathrm{MgO}$ in comparison to $\mathrm{MgF}_{2}$. Evis et al. ${ }^{32}$ could show that the addition of $\mathrm{MgF}_{2}$ to tetragonal zirconia and HA mixtures strongly reduced the tendency of HA decomposition due to partial substitution of $\mathrm{F}^{-}$for $\mathrm{OH}^{-}$ions in the calcium phosphate structure. $\mathrm{MgO}$ is formed in this reaction and can react with tetragonal zirconia to transform it to the cubic phase. Formation of monoclinic phase in the coatings is most likely initiated by different thermal expansion coefficients of the existing phases, which lead to the formation of thermal activated residual stresses during specimen cooling after sintering. These residual stresses can cause a destabilization of tetragonal phase and initiate a transformation to monoclinic zirconia. ${ }^{4}$

All prepared coatings exhibited an irregular but uniform morphology and created a sort of net-like structure all over the substrate surface. We observed that incorporation of magnesium up to $1.6 \%$ do not affect 

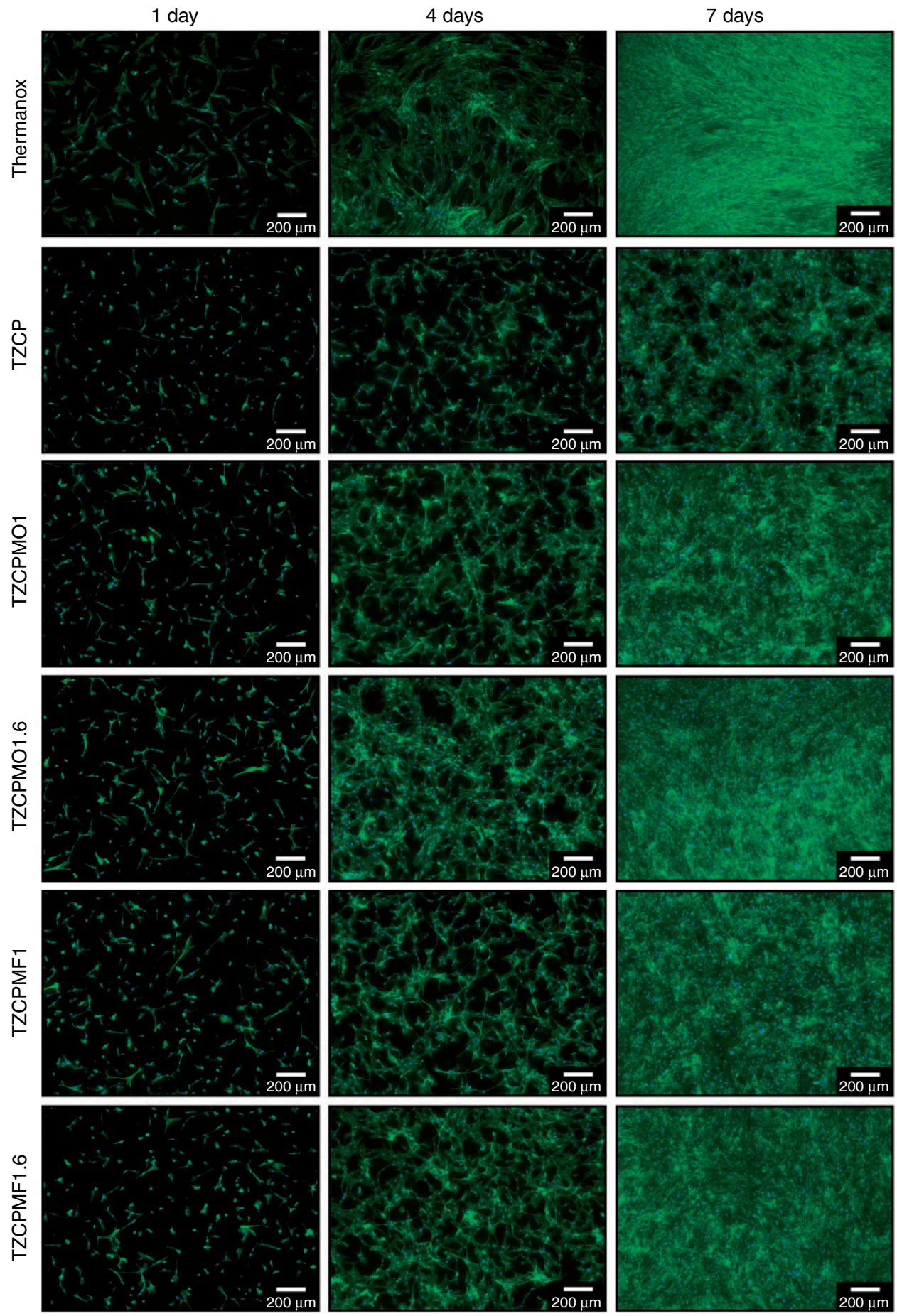

Figure 9. Fluorescence micrograph of $H O B$ on Thermanox ${ }^{\circledR}$ and different coated samples over a culture period of 7 days. The cells were fixed and stained with AF488-phalloidine (green) for actin filaments and with DAPI for nuclei (blue). Typical images are shown for Thermanox ${ }^{\circledR}$ and TZCP (reference) and samples with $\mathrm{MgO}$ and $\mathrm{MgF}_{2}$ addition.

the microstructure appreciably, whereas a higher magnesium content $(2.5 \mathrm{wt} \%)$ induced the formation of granular structures. Furthermore, the sprayed coatings are rough and porous, with pores distributed throughout the coating thickness. A higher porosity and roughness is considered beneficial for biomedical applications due to improved cell attachment and thus better bone ingrowth as reported in Chung and Long. ${ }^{33}$

Biaxial fracture strength investigations, scratch test analysis and dissection experiments of coated zirconia 
implants combined with subsequent SEM observation revealed mechanical stability as well as coating adhesion of the different deposited $\mathrm{Mg}$-containing coatings and the reference coating without $\mathrm{Mg}$-addition. B3B results show the influence of coating composition on the mechanical strength of the bulk material. Sample TZCPMO1 exhibited the highest strength, which was significantly higher than all other tested coatings and comparable with the reference TZCP. Both TZCPMO1 and TZCP possess nearly the same biaxial flexural strength that was found for uncoated $\mathrm{TZ}$ and which is approximately $1100 \mathrm{MPa} .{ }^{19}$ Analysis of the other specimens showed that the strength tends to decrease with increasing $\mathrm{Mg}$-content. Further investigations of the fracture surface revealed an interface layer between coating and substrate, whose thickness increases with enhanced Mg-content. This layer is most likely formed during the sintering process. $\mathrm{CaO}$, released from HA decomposition, diffuses into the $\mathrm{TZ}$ substrate, as it can be determined by EDX analysis, and probably causes a transformation of tetragonal to cubic TZ. In addition, magnesium can also be integrated in $\mathrm{TZ}$ and lead to further stabilization of zirconia. ${ }^{32}$ However, $\mathrm{Mg}$ was not detected in the interface layer by EDX analysis because it was not present or below detection limit of the method used. As can be seen from our GIXRD results, monoclinic zirconia was detected in the coatings besides cubic zirconia. Both cubic and monoclinic zirconia are known to have inferior mechanical properties compared to tetragonal zirconia and could affect the mechanical strength. ${ }^{4}$ However, based on our B3B results and fracture surfaces analysis, we conclude that the interface layer is mainly responsible for the decrease in mechanical strength due to the fact that cubic TZ is unable to stop crack growth by phase transformation. This is supported by the comparison of the $\mathrm{B} 3 \mathrm{~B}$ results of specimens with $\mathrm{Mg}$-containing coatings and the reference sample TZCP. Despite the presence of monoclinic and cubic zirconia in the coating ${ }^{19}$ TZCP exhibits a good and with uncoated TZ comparable mechanical strength since no interface layer between coating and substrate was formed. Therefore, it can be hypothesized that the coating phase composition has only a negligible influence on the strength without the existence of an interface layer. Nevertheless, a possible increase in harmfulness of the interface layer caused by monoclinic phase cannot be excluded. Furthermore, it can be noted that the decrease in mechanical strength clearly correlates with the thickness of the interface layer.

Scratch tests carried out with discs and dissection experiments carried out with coated implants showed a firm coating adhesion. Both analysis methods yielded the same results suggesting no adverse effect of $\mathrm{Mg}$ on coating adhesion, independent of the $\mathrm{Mg}$-content. On the contrary, there is even evidence that $\mathrm{Mg}$ promotes adhesion of coatings. ${ }^{34}$ In our previous work, the low bonding strength of pure $\mathrm{CP}$ coating to TZ substrate was shown, which is known to be one disadvantage. ${ }^{19}$ This improved bonding strength of the mixed coatings in comparison to pure $\mathrm{HA}$ or $\mathrm{CP}$ coatings have the potential for enhanced performance in biomedical applications.

As an implant coating material, not only the coating stability and adhesion play an important role in the performance of implants, both chemical composition and dissolution have also a great impact on cell behavior and thus on the cytotoxicity of implant materials. The results of our dissolution experiments showed that the release of $\mathrm{Ca}^{2+}$ was considerably reduced compared to the reference TZCP and it further decreases with increasing $\mathrm{Mg}$-content. This observation leads to the confirmation that the new CaMgP-phase, formed during heat treatment, possesses a lower dissolution rate than TCP that is present in the TZCP coating after sintering. ${ }^{19}$ This is also in agreement with the results of others that showed a reduction of degradation in $\mathrm{Mg}$ substituted $\mathrm{CP}$ biomaterials. ${ }^{35,36}$ Within the two different $\mathrm{Mg}$-sources the lowest $\mathrm{Ca}^{2+}$ release was observed for $2.5 \mathrm{wt} \% \mathrm{Mg}$-addition, this behavior could be attributed to the morphological change of the coating.

The biological activity of biomaterials is associated with their capability of mineral layer formation when in contact with biological fluids. However, when samples are immersed in SBF dissolution and precipitation will take place at the same time. As a consequence, the concentration of $\mathrm{Ca}$ and $\mathrm{Mg}$ ions and $\mathrm{P}$ groups increase in the solution adjacent the specimen surface, resulting in an increase of supersaturation that is beneficial to nucleation and growth of new mineral layers. In other words, when precipitation is dominant a new mineral layer will form on the sample surface. Our results show that the precipitation of a mineral layer was favored at the surface of samples TZCPMO1 and TZCPMO1.6. In contrast, on reference sample TZCP less precipitation was observed after 21 days immersion (data not shown) suggesting a beneficial effect of $\mathrm{Mg}$ for in vitro behavior although dissolution was lower compared to TZCP. The same observation was made by Gomes et $\mathrm{al}^{36}$ who showed that precipitation was more favored on samples with a less-soluble $\mathrm{Mg}$ substituted $\beta$-TCP phase. All other investigated samples did not exhibit any mineral layer formation, which seemed to be related to the $\mathrm{Mg}$ content in the coating and also to the kind of additive. Coatings with $\mathrm{MgF}_{2}$ addition and with $2.5 \mathrm{wt} \%$ or $5 \mathrm{wt} \% \mathrm{MgO}$ addition showed a lower $\mathrm{Ca}^{2+}$ dissolution and thus the local concentration of dissolved ions was too low to trigger precipitation. In case of sample TZCPMF1.6 precipitation of a new mineral layer was also detected probably due to the 
higher amount of dark gray areas (Figure 2f) exposed at the coating surface that represent the soluble $\mathrm{CaMgP}$ phase. Therefore, we suppose that the local concentration of calcium and phosphate ions was high enough to initiate precipitation.

Protein adsorption and cell adhesion belong to the first stage of interaction between implant materials and cells. The quality of this stage affects the capacity of cell proliferation, growth and differentiation in contact with the investigated implant material. ${ }^{37}$ Therefore, the sample surface has to feature attractive properties to reach a good performance in the biological environment. In the present study the cells appeared to attach and grow well on Mg-containing coatings, since the metabolic activity, cell number, protein content and ALP activity increased with time and were largely comparable with Thermanox ${ }^{\circledR}$. Moreover, considering the whole culture period it can be concluded that coatings with $1.6 \mathrm{wt} \%$ were more supportive than those with $1 \mathrm{wt} \% \mathrm{Mg}$-addition. The reference coating without $\mathrm{Mg}$, however, always provided the poorest results. Therefore, $\mathrm{Mg}$ ions seem to have a stimulating effect on osteoblastic cell response. Previous studies demonstrated similar results where cells on $\mathrm{Mg}$ containing surfaces showed higher proliferation and differentiation compared to Mg-free specimens. ${ }^{30,38,39}$ Furthermore, $\mathrm{Mg}$ ions are considered to be beneficial for bone cell attachment. Zreiqat et al. ${ }^{23}$ reported that cells grown on Mg-modified alumina exhibited a significantly increased adhesion since binding of integrins to specific ligands depends on the presence of divalent cations. ${ }^{23}$

The results presented in this study indicate a positive effect of Mg-addition to improve the bioactivity of TZCP coating suggesting that further investigation is necessary. It should be stated that preclinical in vivo evaluations should be addressed to determine the bioactivity and long-term stability under dynamic physiological conditions. Future work could also include the incorporation of other or further additives to mimic the chemistry of natural bone tissue more accurately.

\section{Conclusion}

The present study focused on the influence of Mg-addition with varying amounts from two different $\mathrm{Mg}$ sources to TZCP coatings on mechanical and chemical stability as well as biological performance using the WPS technique. The characterization of Mg-containing coatings demonstrated a significant decrease in mechanical stability with increasing $\mathrm{Mg}$-content, whereas the coating adhesion was not affected compared to pure TZCP coating. The sintering step led to phase transformations, and thus the development of a bioactive calcium magnesium phosphate phase. Dependent on the Mg-content the studied coatings exhibited different $\mathrm{Ca}^{2+}$ and $\mathrm{Mg}^{2+}$ ion release behavior. In addition, in vitro investigations indicated that $\mathrm{Mg}$-coatings appeared not to be cytotoxic when in contact with HOB. Moreover, the results obtained reveal an improved biological performance caused by the presence of $\mathrm{Mg}^{2+}$ ions.

\section{Acknowledgments}

The authors thank Martin Ellerhorst (BEGO Implant Systems, Bremen, Germany) for providing implant geometries and Andreas Reindl (Fraunhofer IFAM, Bremen, Germany) for zirconia implant preparation. We are grateful to Giovanni Li Destri and Giovanni Marletta (Laboratory for Molecular Surfaces and Nanotechnology, Catania, Italy) and Michael Teck, William Lando and Eduardo Vieira for their help and support in the experimental investigation. We also acknowledge Petra Witte (Historical Geology Palaeontology, University of Bremen, Germany) for the performance of SEM and EDX analysis.

\section{Declaration of Conflicting interests}

None declared.

\section{Funding}

This work was supported by the Deutsche Forschungsgemeinschaft, DFG (grant number RE 2735/7-1).

\section{References}

1. Tschernitschek H, Borchers $\mathrm{L}$ and Geurtsen W. Nonalloyed titanium as a bioinert metal-a review. Quintessence Int 2005; 36: 523-530.

2. Niinomi M. Mechanical biocompatibilities of titanium alloys for biomedical applications. J Mech Behav Biomed Mater 2008; 1: 30-42.

3. Niinomi M. Mechanical properties of biomedical titanium alloys. Mater Sci Eng A 1998; 243: 231-236.

4. Piconi $\mathrm{C}$ and Maccauro G. Zirconia as a ceramic biomaterial. Biomaterials 1999; 20: 1-25.

5. Manicone PF, Rossi Iommetti P and Raffaelli L. An overview of zirconia ceramics: basic properties and clinical applications. J Dent 2007; 35: 819-826.

6. Best SM, Porter a E, Thian ES, et al. Bioceramics: Past, present and for the future. J Eur Ceram Soc 2008; 2: 1319-1327.

7. Montanaro L, Arciola CR, Campoccia D, et al. In vitro effects on MG63 osteoblast-like cells following contact with two roughness-differing fluorohydroxyapatitecoated titanium alloys. Biomaterials 2002; 23: 3651-3659.

8. Liang H, Wan YZ, He F, et al. Bioactivity of Mg-ionimplanted zirconia and titanium. Appl Surf Sci 2007; 253: 3326-3333.

9. Brohede U, Zhao S, Lindberg F, et al. A novel graded bioactive high adhesion implant coating. Appl Surf Sci 2009; 255: 7723-7728. 
10. Hench LL. Bioceramics: from concept to clinic. $J \mathrm{Am}$ Ceram Soc 1991; 74: 1487-1510.

11. Dorozhkin SV. Calcium orthophosphates. J Mater Sci 2007; 42: 1061-1095.

12. Bohner M. Calcium orthophosphates in medicine: from ceramics to calcium phosphate cements. Injury 2000; 31(Suppl 4): 37-47.

13. Jarcho M. Calcium phosphate ceramics as hard tissue prosthetics. Clin Orthop Relat Res 1981; 157: 259-78.

14. Bloebaum RD, Beeks D, Dorr LD, et al. Complications with hydroxyapatite particulate separation in total hip arthroplasty. Clin Orthop Relat Res 1994; 298: 19-26.

15. Overgaard S, Søballe K, Lind M, et al. Resorption of hydroxyapatite and fluorapatite coatings in man. $J$ Bone Jt Surg 1997; 79: 654-659.

16. Ducheyne P. Bioactive ceramics. J Bone Jt Surg. 1994; 76 : 861-862.

17. Matsumoto TJ, An S-H, Ishimoto $\mathrm{T}$, et al. Zirconiahydroxyapatite composite material with micro porous structure. Dent Mater 2011; 27: e205-212.

18. Yugeswaran S, Yoganand CP, Kobayashi A, et al. Mechanical properties, electrochemical corrosion and in-vitro bioactivity of yttria stabilized zirconia reinforced hydroxyapatite coatings prepared by gas tunnel type plasma spraying. J Mech Behav Biomed Mater 2012; 9: 22-33.

19. Pardun K, Treccani L, Volkmann E, et al. Characterization of wet powder-sprayed zirconia/calcium phosphate coating for dental implants. Clin Implant Dent Relat Res 2013; DOI: 10.1111/cid.12071.

20. Staiger MP, Pietak AM, Huadmai J, et al. Magnesium and its alloys as orthopedic biomaterials: a review. Biomaterials 2006; 27: 1728-1734.

21. Kannan S, Lemos AF and Ferreira JMF. Synthesis and Mechanical Performance of Biological-like Hydroxyapatites. Chem Mater 2006; 18: 2181-2186.

22. LeGeros RZ. Calcium phosphates in oral biology and medizine. In: Myers H (ed.) Monographs in oral sciences. Karger Basel Switzerland: 1991; pp.1-201.

23. Zreiqat H, Howlett CR, Zannettino A, et al. Mechanisms of magnesium-stimulated adhesion of osteoblastic cells to commonly used orthopaedic implants. J Biomed Mater Res 2002; 62: 175-184.

24. Landi E, Tampieri A, Mattioli-Belmonte $\mathrm{M}$, et al. Biomimetic $\mathrm{Mg}$ - and $\mathrm{Mg}, \mathrm{CO} 3$-substituted hydroxyapatites: synthesis characterization and in vitro behaviour. $J$ Eur Ceram Soc 2006; 26: 2593-2601.

25. Cowan JA. Structural and catalytic chemistry of magnesium-dependent enzymes. Biometals 2002; 15: 225-235.
26. Wiesmann HP, Tkotz T, Joos U, et al. Magnesium in newly formed dentin mineral of rat incisor. $J$ Bone Miner Res 1997; 12: 380-383.

27. Jiang G and Shi D. Coating of hydroxyapatite on highly porous $\mathrm{A} 12 \mathrm{O} 3$ substrate for bone substitutes. J Biomed Mater Res 1998; 43: 77-81.

28. Börger A, Supancic P and Danzer R. The ball on three balls test for strength testing of brittle discs: stress distribution in the disc. J Eur Ceram Soc 2002; 22: 1425-1436.

29. Oyane A, Kim H-M, Furuya T, et al. Preparation and assessment of revised simulated body fluids. J Biomed Mater Res A 2003; 65: 188-195.

30. Xie Y, Zhai W, Chen L, et al. Preparation and in vitro evaluation of plasma-sprayed $\mathrm{Mg}(2) \mathrm{SiO}(4)$ coating on titanium alloy. Acta Biomater 2009; 5: 2331-2337.

31. Ruder A, Buchkremer HP, Jansen H, et al. Wet powder spraying - a process for the production of coatings. Surf Coatings Technol 1992; 53: 71-74.

32. Evis Z, Usta M and Kutbay I. Improvement in sinterability and phase stability of hydroxyapatite and partially stabilized zirconia composites. J Eur Ceram Soc 2009; 29: 621-628.

33. Chung C-J and Long H-Y. Systematic strontium substitution in hydroxyapatite coatings on titanium via microarc treatment and their osteoblast/osteoclast responses. Acta Biomater 2011; 7: 4081-4087.

34. Qi G, Zhang S, Khor KA, et al. An interfacial study of sol-gel-derived magnesium apatite coatings on Ti6A14V substrates. Thin Solid Films 2008; 516: 5172-5175.

35. Li X, Ito A, Sogo Y, et al. Solubility of Mg-containing beta-tricalcium phosphate at 25 degrees C. Acta Biomater 2009; 5: 508-517.

36. Gomes S, Renaudin G, Jallot E, et al. Structural characterization and biological fluid interaction of Sol-Gelderived Mg-substituted biphasic calcium phosphate ceramics. ACS Appl Mater Interfaces 2009; 1: 505-513.

37. Paital SR and Dahotre NB. Calcium phosphate coatings for bio-implant applications: materials, performance factors, and methodologies. Mater Sci Eng R Reports 2009; 66: 1-70.

38. Cai YL, Zhang JJ, Zhang S, et al. Osteoblastic cell response on fluoridated hydroxyapatite coatings: the effect of magnesium incorporation. Biomed Mater 2010; 5: 054114.

39. Shi X, Nakagawa M, Kawachi G, et al. Surface modification of titanium by hydrothermal treatment in Mg-containing solution and early osteoblast responses. J Mater Sci Mater Med 2012; 23: 1281-1290. 